STONE CENTER ON SOCIO-ECONOMIC INEQUALITY

WORKING PAPER SERIES

No. 21

Intergenerational Transfers by Size and Wealth Inequality in Rich Countries

\author{
Brian Nolan \\ Juan Palomino \\ Philippe Van Kerm \\ Salvatore Morelli
}

September 2020

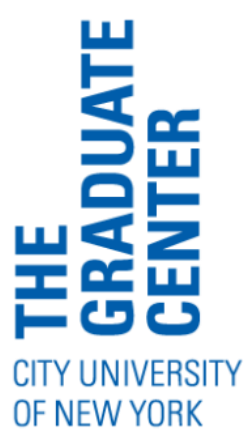




\title{
Intergenerational Transfers by Size and Wealth Inequality in Rich Countries
}

\author{
Brian Nolan $^{\mathrm{a}}$, Juan Palomino ${ }^{\mathrm{a}}$, Philippe Van Kerm ${ }^{\mathrm{b}}$ and Salvatore Morelli ${ }^{\mathrm{c}}$ \\ a INET and Department of Social Policy and Intervention, University of Oxford \\ ${ }^{\mathrm{b}}$ University of Luxembourg and Luxembourg Institute of Socio-economic Research (LISER) \\ ${ }^{c}$ Stone Center on Socio-Economic Inequality, CUNY Graduate Center, New York
}

\begin{abstract}
This paper uses household wealth surveys to compare patterns of intergenerational wealth transfers across six rich countries and assess the relationships between transfers, current levels of net wealth, and wealth inequality. The paper examines four Euro Area countries, France, Germany, Italy, and Spain and extends the systematic comparison to the US and the UK. It finds that many of those currently at the top of the wealth distribution did not benefit from intergenerational transfers, but those who did received particularly large amounts while those toward the bottom of the wealth distribution received very little. A substantial gap in net wealth is seen between those who received or did not receive some wealth transfer. Controlling for age, gender, education and household size reduces the size of that gap but it remains substantial, especially in the US. We further look at how a marginal increase in the proportion of recipients of transfers of differing sizes would contribute to the shape of the overall wealth distribution using influence function regressions. Crucially, we show that the impact depends not only on the locations in the wealth distributions of recipients versus non-recipients, but also on the size of the receipt, an aspect which has been overlooked to date. In most countries, increasing the proportion of recipients of large transfers generally increases overall wealth inequality. In contrast, having more recipients of small or mediumsized transfers would be expected to reduce wealth inequality modestly, as they are more concentrated around the middle of the wealth distribution than non-recipients.
\end{abstract}

Keywords: Wealth, inheritance, inequality, intergenerational transmission JEL: D31

Acknowledgements: Funding from the Nuffield Foundation is gratefully acknowledged. 


\section{Intergenerational Wealth Transfers by Size and Wealth Inequality in Rich Countries}

\section{Introduction}

Transfers of wealth from one generation to the next via inheritance and gifts inter vivos and the role they play in the accumulation of household wealth and generation of wealth inequality have been of long-standing research and policy interest. Piketty $(2011,2014)$ has highlighted the centrality of wealth inequality and the increasing role of intergenerational transmission in that respect, showing that in France the annual wealth transmitted via inheritance and gifts rose from around $2.5 \%$ of national income in 1950 to around $15 \%$ by 2010 . Similarly, Alvaredo, Atkinson, and Morelli (2018) and Acciari and Morelli (2020) show that the aggregate annual transfer via inheritance and gifts has been rising substantially relative to national income in the UK and Italy respectively. A substantial literature has explored the role of intergenerational transfers in the accumulation of wealth and generation of wealth inequality, with some striking conclusions but no consensus emerging. Unlike wealth inequality, where comparative analysis is increasingly common, this literature is almost entirely based on single country studies with just a few looking across countries to date, either at patterns of wealth transfer themselves or at the role these play in wealth inequality.

Here we use microdata from household wealth surveys to investigate the relationship between intergenerational transfer receipt, wealth levels and wealth inequality in six major rich countries. We bring data for France, Germany, Italy and Spain from the Eurozone Household Finances and Consumption Survey (HFCS) together with the US Survey of Consumer Finances (SCF) and the British Wealth and Assets Survey (WAS). This allows us to compare patterns of wealth transfer and the relationships between transfer receipts, wealth levels and wealth inequality across two major 'liberal' economies, two large 'continental European' economies, and two large 'Southern European' countries. The HFCS has provided the data for the few comparative studies of wealth transfers so far and broadening coverage to include Great Britain and the US is informative and not implemented in any depth in the existing literature. The design of the SCF influenced the HFCS and these can be brought together in a relatively straightforward fashion, whereas we have invested significant effort into deriving measures of wealth transfers from the Wealth and Assets Survey aligned with them. 
We review the relevant literature in Section 2 and describe the data sources employed in Section 3. Section 4 compares patterns of wealth transfers received by households across these countries and presents estimated models for how transfers are related to the characteristics of recipient households. Section 5 analyses the relationship between transfer receipt and current wealth levels, and then the role of wealth transfers in wealth inequality by estimating influence function regressions. Section 6 brings together the conclusions and discusses their implications.

Key findings include that about one-third of households report having received some intergenerational wealth transfer in most of the countries, but that figure is only one-fifth in the US. Age and level of education are generally strong predictors both of wealth transfer receipt and amounts received, but the relative advantage of those with tertiary education varies across countries. Having controlled for differences in age and education a substantial gap between the current wealth of transfer recipients and non-recipients remains, with the relationship between transfer receipt and owning one's own house accounting for a substantial proportion of that difference. As far as transfers and wealth inequality is concerned, we find that, counterfactually, having more transfer recipients and correspondingly fewer non-recipients would for the most part reduce wealth inequality, reflecting the fact that these recipients are generally more frequently positioned around the middle of the overall wealth distribution than nonrecipients. When only large transfers are included, however, increasing the proportion of those transfers generally increased overall wealth inequality. These findings serve to reinforce the counterintuitive to many - finding in some recent studies that the overall effect of wealth transfers is equalizing, but highlight a crucial heterogeneity in impact varying with the size of the transfers that has not been recognised before.

\section{Previous Literature on the Role of Wealth Transfers in Wealth in Rich Countries}

A substantial literature has explored the role of intergenerational transfers in the accumulation of wealth and generation of wealth inequality. The overall importance of inherited wealth versus life-cycle saving for wealth inequality has been hotly debated for many years, with the conflicting estimates produced by Kotlikoff and Summers (1981 and 1988) and Modigliani, (1988) being a common point of reference (see also the overview by Davies and Shorrocks, 2000). More recently, studies based on microdata have generally arrived at the, to many surprising, conclusion that inheritances are wealth-equalising. Some of these are based on data from household surveys. Wolff (2002) and Wolff and Gittleman (2014) used data from the US 
Survey of Consumer Finances and Panel Study of Income Dynamics and found that inheritances and other wealth transfers were equalising with respect to the distribution of current wealth. Klevmarken (2004) used data from the Swedish Household Panel Survey and also found an equalising effect of inheritances and gifts on the distribution of current wealth. Karagiannaki and Hills (2013) and Karagiannaki (2017) analyse the annual flow of inheritances and gifts reported in the British Household Panel Survey from 1996-2005, and conclude that these had only a limited impact on wealth inequality. ${ }^{1}$ Crawford and Hood (2016) analyse data on lifetime receipt of inheritances and gifts of older persons from English Longitudinal Study of Ageing, compare inequality in transfers and in wealth minus transfers and conclude that inheritances and gifts are equalising in terms of conventional measures of marketable wealth. Others are based on tax records/administrative data. With Swedish data, Elinder et al (2018) inheritances find that inheritances reduce relative wealth inequality, as measured by the Gini coefficient or top wealth shares, but that they increase absolute dispersion. Using Danish tax records Boserup et al (2016) find that inheritances increase absolute wealth inequality but reduce relative inequality measures such as the top $1 \%$ share. However, Nekoei and Seim (2019) find that this inequality-reducing effect does not last a decade as fewer wealthy heirs deplete their inherited wealth in contrast to more affluent heirs.

Most of these studies have been for individual countries, reflecting the national specificity of tax-based data and the absence until recently of survey-based data that was sufficiently comparable in terms of the information sought. The recent development of the Luxembourg Wealth Study and in particular the implementation of the Household Finances and Costs Surveys (HFCS) across the Eurozone countries has fundamentally altered this landscape. As far as patterns of wealth transfer are concerned, Fessler, Mooslechner and Schürz (2008) employed microdata from an early version of the Luxembourg Wealth Study to compare the characteristics of those receiving versus not receiving transfers but highlight major differences across countries in the way transfer receipt was measured which seriously undermined their comparability. Fessler and Schürz (2018) use data for thirteen European countries from the HFCS to compare the percentage of households having received an inheritance across these countries. Cowell et al. (2018) use LWS data for five Eurozone countries together with Australia, the UK and the US to compare the percentage of households reporting receipt of

\footnotetext{
${ }^{1}$ Karagiannaki (2011) also looked at gifts as well as inheritances in the 2004 Attitudes to Inheritance Survey, while Karagiannaki (2015) also included summary information from the early waves of the Wealth and Assets Survey, the British source on which we rely here.
} 
wealth transfers and the amounts received across the wealth distribution. Balestra and Tonkin's (2019) study for the OECD reports inter alia patterns of wealth transfer receipt by age and income for HFCS countries plus Canada.

On the role of wealth transfers in household wealth accumulation and inequality, Fessler and Schürz (2015) also compare the net wealth of these households versus those which did not inherit, and employ regression analysis to show that, on average, having received an inheritance is associated with a household being about 14 percentiles higher in their country's net wealth distribution. Leitner (2016) uses HFCS data for eight Eurozone countries to apply the Shapley value decomposition approach to measure the contribution of inheritances and gifts to gross and net wealth inequality, finding on that basis that inheritances explain/contribute between $14 \%$ and $30 \%$ of wealth inequality as measured by the Gini index.

Here we broaden the country coverage beyond HFCS to include Great Britain and the US, compare patterns of wealth transfer across six major economies in some detail, and employ a different analytical approach to assessing the role of wealth transfers in wealth inequality which we argue has significant advantages in tackling this complex and contested issue.

\section{Data and Variables}

This paper exploits the availability of micro-data from specially-designed surveys of wealth and related topics for large representative samples of households in our selected countries, and these are now described.

The SFC has been carried out in the US by the Federal Reserve every third year since 1983. It is generally a cross-section survey with a new sample each wave (though there have been occasional longitudinal elements). The SCF oversamples towards the top of the distribution to improve its capacity to capture high-wealth cases and measure top wealth shares (see for example Bricker et al, 2016), and seems able to do so particularly effectively compared with other countries. It does so via a dual-frame sample design, whereby a nationally representative set of families selected from an address-based sampling frame is supplemented with an oversample of wealthy families drawn from a list provided by the Internal Revenue Service from individual income tax returns. The information on those returns on income from different types of asset is used to predict wealth and allow the survey to disproportionately select the 
relatively wealthy (see Bricker et al, 2017). The complex set of weights provided take into account inter alia this sampling design in order to produce a representative sample of the population as a whole.

The HFCS began around 2010 and is carried out every 3-4 years across member countries of the Eurozone. It is implemented by national central banks or statistical offices, coordinated by the ECB in conjunction with the Household Finance and Consumption Network (HFCN) it established in 2006 to ensure the application of a common methodology, pool and qualitycontrol the country datasets and disseminate the survey results and microdata. The fieldwork for the first wave was carried out in most countries in 2010 or 2010-11 (2008-09 in Spain, 2009-10 in France, 2009 in Greece), with the second wave generally around 2014 and a third wave around 2017. Fifteen of the 17 Eurozone countries took part in the first wave (see Household Finance and Consumption Network, 2013). The HFCS is primarily a cross-sectional survey, with longitudinal elements in some countries. Nine of the fifteen countries participating in Wave 1 had some oversampling of the wealthy, most often based on geographical location but in some cases employing information on wealth or income. The effective oversampling rates in the first wave of the survey can be seen to vary widely across countries, with France, Germany and Spain having particularly high rates but Italy not oversampling. There are also differences in the sample selection and consequently in weighting procedures, and while a common Eurosystem blueprint questionnaire is the starting point there are some differences across the national questionnaires for a variety of reasons.

The WAS is a longitudinal survey carried out by the Office for National Statistics (ONS) specifically to capture household wealth and its evolution over time in Great Britain (that is England, Scotland and Wales rather than the UK which also includes Northern Ireland).The first wave of interviews was carried out from mid-2006 to mid-2008, and the latest wave for which results have been published, Wave 6, was in the field from mid-2016 to mid-2018. In light of the substantial attrition seen in the first two waves, the third and subsequent waves included both 'continuing' households and a new supplemented or 'refreshed' sample. In order to increase the likelihood of including households towards the top of the wealth distribution, the WAS applies an oversampling strategy based on geographical areas. The longitudinal structure of WAS significantly complicates its use for current purposes because of the way information about receipt of wealth transfers was gathered, as we shall see. 
The SCF, HFCS and WAS each seek in-depth information from responding households about their assets and debts - that is central to their purpose. This covers real assets such as the main residence, other real estate property, vehicles, valuables such as jewellery, antiques or art, and business wealth, as well as financial assets such as bank and other deposits, stocks and shares, and voluntary private pension assets. Net wealth comprises the aggregate value of all these assets held minus debt outstanding in the form of mortgages, overdrafts, credit card debt, car loans, consumer loans, instalment and other loans. ${ }^{2}$ The wealth concept we employ does not include the value of private occupational pensions or of entitlements to public pensions, as these are very difficult to assess in a robust and comparable way across countries.

The SCF seeks details on inheritances and gifts received by household members at any point over their lifetime. Respondents are asked whether they or their partner have ever received an inheritance, or been given substantial assets in a trust or some other form, and if so how many. For each of the largest three, they are then asked if it was an inheritance, trust, or transfer/gift, the approximate value when received, the year of receipt, and from whom it was received. Where there were any other receipts (apart from the three largest), their total market value taken together is also sought.

The HFCS similarly seeks details on inheritances and gifts received by household members at any point over their lifetime. The blueprint questionnaire asks the main household respondent if their current main residence was acquired by inheritance or received as a gift. It then asks whether, in addition to the household main residence, they or any member of the household has ever received an inheritance or a substantial gift, including money or any other assets, from someone who is not a part of the current household. If so, the respondent is asked how many were received and for each of the largest three the year received, what kinds of assets were involved, how much was it worth at the time, whether it was a gift or an inheritance, and from whom it was received. We aggregate these to arrive at the total value of transfers in either form. ${ }^{3}$

\footnotetext{
${ }^{2}$ Note that this measure of household wealth differs from that used by the UK Office for National Statistics in its publications based on WAS, which does not include the estimated value of own businesses and does include the value of "household contents".

${ }^{3}$ Where the original or the current value of the main residence reported by the respondent is equal to the value of any of the other inheritances reported we only include this once to avoid the risk of doublecounting. Contact with the data producers in each country, facilitated by the ECB, has been helpful in identifying some important differences in the way the common template has been adapted for national use and relevant variables produced. For example, for Spain if the main residence was inherited one
} 
The WAS takes a different approach in gathering information on receipt of wealth transfers, reflecting its longitudinal design. Information about lifetime inheritances was only sought in the first wave, with each subsequent wave asking only about transfers received in the two years since the previous wave. Since both inheritances over the lifetime and income are needed, we employ data from Wave 3 covering 2010-2012, but only including the 'continuing' longitudinal households present since the first wave, for whom we then have (in principle) information on inheritances received at any time before Wave 1 plus those received between then and Waves 2 and 3. This reduces the available sample size substantially below its level in Wave 1, but at 13,394 households it remains substantial; the continuing sample (after reweighting) is also similar to both the full supplemented Wave 3 sample and the initial Wave 1 sample in terms of key demographic and other characteristics. Unfortunately, information of gifts was sought only for the preceding two years in each wave including Wave 1, so for those only the six years preceding Wave 3 are covered. However, gifts are mostly much smaller in size than inheritances for Britain so most of the transfer amounts received are still being captured. Other significant issues with respect to the information on transfer receipts in WAS also arise, including imputation of many missing values in Wave 1 for amounts received, the inclusion of small gifts, and the fact that amounts were after tax whereas in SCF and HFCS they are before tax. The ways in which these were addressed in producing the variables employed here are set out briefly in Appendix 1 and in detail in Nolan et al., (2020).

Wealth transfer receipts, and wealth levels, are measured at the household level in the HFCS, based on the definition of a household commonly employed in a survey context as a person living alone or a group of people who live together in the same private dwelling and sharing expenditures, including the joint provision of the essentials of living. ${ }^{4}$ The SCF employs what it terms the 'Primary Economic Unit' (PEU), comprising an individual or couple and others in the household who are financially interdependent; this is narrower than the household but most households comprise only one PEU. ${ }^{5}$ In the WAS information on both wealth and wealth transfers is sought from each adult, so we aggregate these to the household level. Inheritances

needs to add its value to the inheritance amount reported in the direct question about inheritance, whereas for Italy the main residence is included in that inheritance question.

${ }^{4}$ For details see HFCN (2016) Appendices pp. 90-91.

${ }^{5}$ In the 2016 SCF dataset, $13 \%$ of PEUs were in a household that also contained one or more members not in that PEU. 
from a deceased spouse are excluded in both SCF and HFCS but are covered in the WAS and excluded here. To align timing across the surveys we employ data from Wave 1 of the HFCS, the SCF for 2010, and Wave 3 of the WAS. ${ }^{6}$ As the amounts for inheritances and gifts received at different points in time are reported in nominal values at the time of receipt, to put these on a common basis we update them to values at the time of the survey (usually 2010) using the change in the consumer price index since then.

\section{Receipt of Intergenerational Wealth Transfers}

\subsection{Descriptive Patterns}

We first present a descriptive picture of the extent and nature of receipt of intergenerational transfers from analysis of these datasets. Table 1 shows the incidence of receipt of inheritances, gifts and either for each country. The percentage reporting receipt of an inheritance ranges from $17 \%$ in the US up to $28-30 \%$ for Spain and Britain, with the other countries between $22-26 \%$. Substantial gifts are most frequently reported in France and Germany, at $12 \%$ and 17\% respectively, Britain and Italy are at $7-8 \%$, and very few gifts are seen in the cases of Spain and the US, though the figure for Spain must be heavily qualified. ${ }^{7}$ Taking inheritances and gifts together, about one-third of households report some receipt in Britain, France, Germany and Italy, with Spain slightly lower but the US a clear outlier with only $19 \%$ of households reporting receipt.

Table 1: Percentage Receiving Intergenerational Transfers

\begin{tabular}{lcccccc}
\hline & Britain & France & Germany & Italy & Spain & US \\
\hline \multirow{3}{*}{ Inheritances } & $\%$ & $\%$ & $\%$ & $\%$ & $\%$ & $\%$ \\
Gifts & 29.6 & 22.2 & 22.7 & 25.7 & 28.0 & 17.1 \\
Inheritances or Gifts & 34.7 & 36.1 & 32.5 & 31.6 & 28.8 & 19.1 \\
\hline
\end{tabular}

\footnotetext{
${ }^{6}$ It would have been possible to use data from later waves of the HFCS and more recent SCF data, but with WAS the number of 'continuing' households from Wave 1, the only ones with lengthy retrospective data on transfer receipt, are an even smaller proportion of the total sample after Wave 3. ${ }^{7}$ The breakdown between inheritances and gifts is often missing in the HFCS for Spain as it was not sought in the underlying Spanish survey (which pre-dates the HFCS) in the case of transfers in the form of financial assets, which are therefore all counted as inheritances. As noted in Section2, the gifts figure for Britain is also biased downwards by the fact that the retrospective observation window available for gifts in WAS Wave 3 was only the previous six years.
} 
Turning to the amounts received as intergenerational transfers in the various countries, and aggregating inheritances and gifts, the mean and median for the aggregate transfers received are shown in Table 2. (Mean and median amounts for inheritances are much larger than gifts in Britain and the US, but for the other countries are similar in size). Both average and median transfer receipts are lowest for Britain and highest for Italy. The mean/median ratio, one indicator of inequality in transfer receipts among recipients, ranges from 2 in Italy to over 4 in France and the US.

Table 2: Intergenerational Wealth Transfers Amounts

\begin{tabular}{|c|c|c|c|c|c|c|}
\hline & Britain & France & Germany & Italy & Spain & US \\
\hline & $£$ & $€$ & $€$ & $€$ & $€$ & $\$$ \\
\hline $\begin{array}{l}\text { Median transfers - } \\
\text { recipient households }\end{array}$ & 34,200 & 44,667 & 80,000 & 150,000 & 79,463 & 68,851 \\
\hline $\begin{array}{l}\text { Mean transfers - } \\
\text { recipient households }\end{array}$ & 115,905 & 189,977 & 184,525 & 295,085 & 224,550 & 281,597 \\
\hline $\begin{array}{l}\text { Median/mean transfers } \\
\text { - recipient households }\end{array}$ & 3.4 & 4.2 & 2.3 & 2.0 & 2.8 & 4.1 \\
\hline $\begin{array}{l}\text { Mean transfers - all } \\
\text { households }\end{array}$ & 40,172 & 68,498 & 59,956 & 93,318 & 64,610 & 53,667 \\
\hline $\begin{array}{l}\text { Mean wealth - all } \\
\text { households }\end{array}$ & 222,073 & 214,451 & 184,256 & 224,500 & 285,178 & 442,325 \\
\hline $\begin{array}{l}\text { Mean transfers as \% } \\
\text { mean wealth - all } \\
\text { households }\end{array}$ & 18.1 & 31.9 & 32.5 & 41.6 & 22.7 & 12.1 \\
\hline
\end{tabular}

Bringing together the percentage of households receiving any transfer with the average amount they received, we can derive the average wealth transfer amounts across all households in each country, and Table 2 also shows these and compares them with the mean levels of net wealth reported held by households. We see that mean transfers captured in the surveys range from $12 \%$ of mean wealth for the US up to over $40 \%$ for Italy. In-depth investigation of the many factors that could underlie this variation is clearly of major interest but beyond the scope of this study. For Britain, Spain and the US inheritance accounts for $90 \%$ or more of the total amount transferred, for Italy that figure is closer to four-fifths, whereas for France and Germany about two-thirds of the total transfer took place via inheritances with one-third through gifts. This is likely to reflect inter alia the structure of taxation of inheritance versus gifts in the various countries (on which see Nolan et al., 2020). 
One would expect the receipt of inheritances and gifts from the previous generation to be strongly related to where individuals and their parents are in their life-cycles. Distinguishing four age groups in terms of the age of the household 'reference person' or equivalent in the surveys we are employing, Table 3 first shows the percentage in each age category reporting receipt of some inheritances and/or gifts. We see that some receipt is quite common across the entire age distribution, often affecting about one in three or one in four households, though in the US few under 35 report any. The table then shows the average transfer receipt for the age group expressed as a ratio of the overall average receipt. These are consistently lowest for the youngest age group but then show considerable variation across countries in how the middle and older age groups compare. Taking incidence and size of receipts together, the final part of Table 3 shows that across all the countries very little of the total amount transferred, typically only about $5 \%$, has been received by the youngest age group. Those aged 65 or more have had the longest time to accumulate transfers and received the largest share of the total in Britain, Italy, the US and especially France, but the 'middle-aged' have done so in Germany and Spain.

Table 3: Intergenerational Wealth Transfers by Age

\begin{tabular}{ccccccc}
\hline Inheritances or gifts & Britain & France & Germany & Italy & Spain & US \\
\hline \% receiving & $\%$ & $\%$ & $\%$ & $\%$ & $\%$ & $\%$ \\
Under 35 & 31.7 & 19.9 & 15.9 & 18.3 & 15.9 & 8.5 \\
35 to 54 & 31.5 & 31.7 & 35.0 & 28.6 & 25.2 & 15.5 \\
55 to 64 & 42.9 & 46.8 & 43.9 & 39.6 & 38.8 & 28.7 \\
Over 65 & 35.2 & 42.9 & 34.2 & 34.2 & 35.2 & 29.1 \\
\hline Ratio of median amount & & & & & & \\
received to overall median & & & & Ratio & & \\
Under 35 & 0.4 & 0.3 & 0.5 & 0.5 & 0.6 & 0.5 \\
35 to 54 & 0.6 & 0.6 & 1.2 & 1.0 & 0.8 & 0.9 \\
55 to 64 & 1.5 & 0.8 & 0.9 & 0.9 & 1.7 & 1.1 \\
Over 65 & 1.3 & 1.8 & 0.9 & 1.2 & 0.8 & 1.2 \\
\hline Total amount received & & & & & & \\
as \% of all transfers & $\%$ & $\%$ & $\%$ & $\%$ & $\%$ & $\%$ \\
Under 35 & 4.6 & 3.8 & 4.6 & 2.3 & 4.9 & 4.6 \\
35 to 54 & 23.4 & 18.6 & 51.1 & 34.0 & 31.2 & 29.2 \\
55 to 64 & 32.4 & 20.4 & 17.4 & 19.1 & 36.2 & 27.8 \\
Over 65 & 39.5 & 57.3 & 26.9 & 44.6 & 27.7 & 38.4 \\
\hline
\end{tabular}


We now look at the way in which intergenerational transfers received by households vary with current income at the time of the survey, using the income variable available in these wealth surveys which is total gross household income (that is, including social protection transfers received but before income tax and social security contributions are deducted); we 'equivalise' this to take the number of persons in the household into account using the square root of household size equivalence scale. Table 4 shows the percentage receiving some wealth transfer for each quarter of households ranked by income and also for the top $10 \%$ and top $1 \%$. The proportion reporting receipt generally rises with income, but the variation is often not so strong, and a substantial number of households in the bottom quarter and half of the income distribution have benefitted from transfers. There is also often little variation in the incidence of receipt towards the top of the distribution, with the top $1 \%$ not more likely to have benefitted from a transfer than the rest of the top decile. (The US is an exception in that respect with some increase in the proportion benefitting from receipt as we move from the top quarter to the top $10 \%$ and then top $1 \%$, though even that increase is relatively modest.)

The middle part of Table 4 then shows how amounts received by those reporting some transfer receipt vary across the income distribution. Mean amounts received generally rise as one moves up the income distribution, though there are several exceptions (with the bottom quartile receiving more on average than the second quartile in France and the US.. The variation across the quartiles of the distribution is again relatively limited except at the very top in Britain, Spain and the US, and to a lesser extent in France where the average receipt for the top $1 \%$ is much higher than for the top decile.

The final part of the table shows how the total amounts received as wealth transfers are distributed across the income distribution, reflecting the combined effect of variation in the proportion receiving and in the average amount received. Households in the top quartile generally received $40 \%-50 \%$ of total transfers compared with about $10 \%-15 \%$ for the bottom quartile (though the latter figure is $20 \%$ for the US). Those in the top $1 \%$ of the income distribution received $8 \%-10 \%$ of the total amount transferred in Britain, France, Spain and the US, but much less than that in Germany and Italy. 
Table 4: Intergenerational Wealth Transfers by Current Income

\begin{tabular}{|c|c|c|c|c|c|c|}
\hline Inheritances or gifts & Britain & France & Germany & Italy & Spain & $U S$ \\
\hline$\%$ receiving & $\%$ & $\%$ & $\%$ & $\%$ & $\%$ & $\%$ \\
\hline First Quartile & 20.8 & 22.9 & 22.0 & 26.7 & 27.6 & 21.1 \\
\hline Second Quartile & 29.1 & 29.3 & 23.2 & 29.8 & 27.7 & 14.0 \\
\hline Third Quartile & 38.4 & 38.0 & 40.8 & 31.8 & 28.3 & 18.9 \\
\hline Fourth Quartile & 50.3 & 50.5 & 44.4 & 38.7 & 31.6 & 23.2 \\
\hline Top Decile & 51.3 & 54.5 & 51.8 & 41.3 & 33.2 & 27.9 \\
\hline Top $1 \%$ & 49.3 & 63.3 & 47.3 & 40.2 & 52.2 & 30.5 \\
\hline $\begin{array}{l}\text { Ratio of median amount } \\
\text { received to overall median }\end{array}$ & \multicolumn{6}{|c|}{ Ratio } \\
\hline First Quartile & 0.7 & 0.9 & 0.6 & 0.6 & 0.5 & 1.1 \\
\hline Second Quartile & 0.8 & 0.6 & 0.7 & 0.7 & 0.7 & 0.7 \\
\hline Third Quartile & 1.0 & 0.7 & 1.2 & 0.9 & 1.4 & 0.7 \\
\hline Fourth Quartile & 1.3 & 1.5 & 1.2 & 1.5 & 1.3 & 1.3 \\
\hline Top Decile & 1.8 & 2.1 & 1.4 & 2.0 & 2.0 & 2.0 \\
\hline Top $1 \%$ & 6.4 & 3.9 & 1.7 & 2.7 & 6.0 & 5.0 \\
\hline $\begin{array}{l}\text { Total amount received } \\
\text { as \% of all transfers }\end{array}$ & $\%$ & $\%$ & $\%$ & $\%$ & $\%$ & $\%$ \\
\hline First Quartile & 9.7 & 15.3 & 9.2 & 11.5 & 12.4 & 19.5 \\
\hline Second Quartile & 17.3 & 12.6 & 12.8 & 16.5 & 15.7 & 14.1 \\
\hline Third Quartile & 27.0 & 17.6 & 36.2 & 23.6 & 34.9 & 18.1 \\
\hline Fourth Quartile & 46.0 & 54.5 & 41.8 & 47.1 & 36.9 & 40.7 \\
\hline Top Decile & 27.3 & 33.2 & 22.1 & 26.6 & 22.9 & 29.1 \\
\hline Top $1 \%$ & 9.1 & 7.9 & 2.4 & 3.4 & 10.2 & 8.1 \\
\hline
\end{tabular}

The pattern of intergenerational transfer receipt by current position in the wealth distribution is of particular interest in thinking about their potential influence on wealth accumulation and inequality. To assess this we rank households by their net worth in terms of total household assets excluding public and occupational pensions minus total outstanding liabilities as outlined earlier. Table 5 shows first that the likelihood of having received an inheritance or gift increases rather consistently across these countries as one moves up the wealth distribution, except at the very top where the figure for the top $1 \%$ is not markedly different from the top decile. It is noteworthy that in five of the six countries a substantial minority of those in the top $1 \%$ reported no inheritance or gift receipt, and in the US only $39 \%$ reported any receipt. 
Table 5: Intergenerational Wealth Transfers by Current Wealth

\begin{tabular}{|c|c|c|c|c|c|c|}
\hline Inheritances or gifts & Britain & France & Germany & Italy & Spain & $U S$ \\
\hline$\%$ receiving & $\%$ & $\%$ & $\%$ & $\%$ & $\%$ & $\%$ \\
\hline First Quartile & 14.9 & 11.7 & 6.4 & 3.4 & 14.9 & 5.7 \\
\hline Second Quartile & 29.4 & 28.5 & 21.0 & 34.6 & 24.6 & 11.6 \\
\hline Third Quartile & 38.2 & 41.6 & 40.9 & 39.4 & 31.1 & 23.0 \\
\hline Fourth Quartile & 56.1 & 58.8 & 61.8 & 49.2 & 44.5 & 35.9 \\
\hline Top Decile & 62.4 & 67.8 & 62.7 & 54.7 & 51.9 & 42.8 \\
\hline Top $1 \%$ & 63.3 & 71.5 & 69.7 & 53.9 & 60.5 & 39.2 \\
\hline $\begin{array}{l}\text { Ratio of median amount } \\
\text { received to overall median }\end{array}$ & \multicolumn{6}{|c|}{ Ratio } \\
\hline First Quartile & 0.4 & 0.3 & 0.2 & 0.2 & 0.2 & 0.1 \\
\hline Second Quartile & 0.5 & 0.6 & 0.2 & 0.4 & 0.4 & 0.3 \\
\hline Third Quartile & 0.7 & 0.6 & 0.6 & 0.6 & 0.5 & 0.3 \\
\hline Fourth Quartile & 1.6 & 1.6 & 1.7 & 1.8 & 1.9 & 1.8 \\
\hline Top Decile & 2.4 & 2.4 & 2.8 & 2.5 & 3.2 & 2.6 \\
\hline Top $1 \%$ & 6.9 & 7.1 & 8.9 & 6.8 & 5.8 & 8.9 \\
\hline $\begin{array}{l}\text { Total amount received } \\
\text { as \% of all transfers }\end{array}$ & $\%$ & $\%$ & $\%$ & $\%$ & $\%$ & $\%$ \\
\hline First Quartile & 4.5 & 2.7 & 1.1 & 0.6 & 2.8 & 1.0 \\
\hline Second Quartile & 11.3 & 13.1 & 2.9 & 10.3 & 7.9 & 5.2 \\
\hline Third Quartile & 18.8 & 18.1 & 17.6 & 19.6 & 14.6 & 10.0 \\
\hline Fourth Quartile & 65.4 & 66.0 & 78.4 & 69.5 & 74.7 & 83.8 \\
\hline Top Decile & 42.5 & 45.4 & 54.5 & 49.3 & 56.8 & 58.7 \\
\hline Top $1 \%$ & 12.6 & 14.4 & 18.6 & 11.6 & 12.2 & 18.2 \\
\hline
\end{tabular}

However, this needs to be seen alongside the patterning of the average amount received shown in the middle part of the table. These amounts generally also rise as one moves up the wealth distribution but are by far the largest for recipients in the top $1 \%$. So while a substantial proportion of those now in the top $1 \%$ of the wealth distribution did not benefit from receipt of intergenerational transfers, those who did received particularly large amounts on average, which can only have been beneficial to their accumulation of wealth. Table 4 finally shows how the total amounts reported as transfers are distributed across the wealth distribution, reflecting the combined effects of varying incidence and average receipts. The share going to the bottom quarter is often very low indeed, no more than $1 \%$ in Germany, Italy and the US. Households in the top $1 \%$, by contrast, received about $13 \%$ of the total amount transferred in Britain, and $18 \%$ in Germany and the US. This exceptionally high degree of concentration in 
Germany and the US is not because more of the transfer recipients are located there, but reflects the exceptional size of the amounts they received.

It is important to note that the observed pattern of transfer receipt is not primarily driven by the fact that both transfer receipt and position in the wealth distribution are systematically related to age. Detailed cross-tabulations (available from the authors) show that within age-groups amounts received still generally rise as one moves up the wealth distribution (though the bottom quartile is sometimes not as distant from the rest) and the most striking feature remains the very large amounts going to recipients right at the top of the distribution.

\subsection{Modelling Receipt of Intergenerational Transfers}

We now move beyond descriptive patterns to statistical analysis of transfer receipt incorporating a range of characteristics and their inter-relationships. We first investigate the characteristics associated with whether the household has received any transfers, irrespective of size, and then assess among recipients only the characteristics associated with receiving larger versus smaller amounts - the two-stage approach often employed in such contexts where many observations have zero receipts (e.g. Crawford and Hood, 2016). We first estimate a logit regression for the probability of receipt, with age, gender and education of the household reference person as independent variables. Table 6 presents the results, in which age is seen to be a major factor in predicting whether some transfer has been received in all six countries. The steepness of this age effect is particularly marked in France and the US and less pronounced in Britain than elsewhere. Households with a male reference person are also significantly more likely to have received a transfer in Britain and France, but there is little or no such difference elsewhere. Those with higher levels of education are more likely to have received an inheritance or gift in most countries, with Spain the notable exception. The relative advantage of those with tertiary education in this respect is relatively marked in Britain, France, Germany and the US, where someone with a third-level qualification was between $22 \%$ and $28 \%$ more likely to have received some intergenerational transfer than someone with only lower secondary education, while the gap was more modest though still statistically significant for Italy. 
Table 6: Regression Analysis of Receipt of Intergenerational Transfer

Intercept

Age 40s

Age 50s

Age 60s or over

Male Head/Reference Person

Higher Secondary Education

Tertiary Education

Intercept

Age 40s

Age 50s

Age 60 s or over

Male Head/Reference Person

Higher Secondary Education

Tertiary Education

(Intercept)

Age 40s

Age 50s

Age 60s or over

Male Head

Higher Secondary Edu

Tertiary Edu

Intercept

Age 40s

Age 50s

Age 60s or over

Male Head/Reference Person

Higher Secondary Education

Tertiary Education

\begin{tabular}{cccc} 
Estimate & Pr(>|t) $)$ & $\begin{array}{c}\text { Britain } \\
\text { Odds }(\% \\
\text { increase })\end{array}$ & $\begin{array}{c}\text { Prob }(\% \\
\text { increase) }\end{array}$ \\
\hline-1.725 & 0.000 & & \\
0.051 & 0.493 & 5.2 & $\mathbf{1 . 3}$ \\
0.404 & 0.000 & 49.8 & $\mathbf{1 0 . 0}$ \\
0.627 & 0.000 & 87.3 & $\mathbf{1 5 . 2}$ \\
0.216 & 0.000 & 24.1 & $\mathbf{5 . 4}$ \\
0.609 & 0.000 & 83.8 & $\mathbf{1 4 . 8}$ \\
1.292 & 0.000 & 263.9 & $\mathbf{2 8 . 4}$ \\
\hline & & France & \\
Estimate & Pr$(>\mid \mathbf{t})$ & Odds $(\%$ & Prob $(\%$ \\
increase) & increase) \\
\hline-2.117 & 0.000 & & \\
0.578 & 0.000 & 78.3 & $\mathbf{1 4 . 1}$ \\
1.144 & 0.000 & 214.0 & $\mathbf{2 5 . 8}$ \\
1.505 & 0.000 & 350.5 & $\mathbf{3 1 . 8}$ \\
0.236 & 0.000 & 26.7 & $\mathbf{5 . 9}$ \\
0.492 & 0.000 & 63.6 & $\mathbf{1 2 . 1}$ \\
1.174 & 0.000 & 223.5 & $\mathbf{2 6 . 4}$ \\
\hline & &
\end{tabular}

\begin{tabular}{cccc}
\hline \multicolumn{3}{c}{ Germany } & \\
Estimate & $\operatorname{Pr}(>|\mathbf{t}|)$ & $\begin{array}{c}\text { Odds (\% } \\
\text { increase) }\end{array}$ & $\begin{array}{c}\text { Prob (\% } \\
\text { increase) }\end{array}$ \\
\hline-2.095 & 0.000 & & \\
0.905 & 0.000 & 147.1 & $\mathbf{2 1 . 2}$ \\
1.009 & 0.000 & 174.2 & $\mathbf{2 3 . 3}$ \\
0.991 & 0.000 & 169.5 & $\mathbf{2 2 . 9}$ \\
-0.014 & 0.902 & -1.3 & -0.3 \\
0.483 & 0.007 & 62.1 & $\mathbf{1 1 . 8}$ \\
1.139 & 0.000 & 212.4 & $\mathbf{2 5 . 8}$ \\
\hline
\end{tabular}

\begin{tabular}{cccc}
\hline Estimate & $\operatorname{Pr}(>|\mathbf{t}|)$ & $\begin{array}{c}\text { Italy } \\
\text { Odds (\%) } \\
\text { increase) }\end{array}$ & $\begin{array}{c}\text { Prob (\%) } \\
\text { increase) }\end{array}$ \\
\hline-1.680 & 0.000 & & \\
0.579 & 0.000 & 78.4 & $\mathbf{1 4 . 1}$ \\
0.935 & 0.000 & 154.7 & $\mathbf{2 1 . 8}$ \\
0.995 & 0.000 & 170.5 & $\mathbf{2 3 . 0}$ \\
0.017 & 0.791 & 1.7 & 0.4 \\
0.184 & 0.011 & 20.2 & $\mathbf{4 . 6}$ \\
0.530 & 0.000 & 70.0 & $\mathbf{1 3 . 0}$ \\
\hline
\end{tabular}




\begin{tabular}{lcccc}
\cline { 2 - 4 } & Estimate & Pr(>|t|) & $\begin{array}{c}\text { Spain } \\
\text { Odds }(\%)\end{array}$ & $\begin{array}{c}\text { Prob (\%) } \\
\text { increase) }\end{array}$ \\
\cline { 2 - 5 } increase)
\end{tabular}

Note: Probabilities in bold are statistically significant from zero at the $1 \%$ level, those in italics are significant at the $5 \%$ level.

To probe the characteristics associated with the varying size of transfers received, we estimate for transfer recipients only a linear regression with the value of that receipt (in log form) as dependent variable. Table 7 shows that the amount received in total via inheritance or gifts tends to be higher for those who are currently older, though this is relatively limited in the cases of Italy and Spain but stronger for Britain, France and the US. Having a male household reference person generally makes little difference to the expected size of transfers received. Having third-level education is associated with marked increases in the predicted size of transfer. For Britain, for example, a household where the reference person has tertiary education would expect to have received $68 \%$ more on average than one where he or she has only lower secondary education. That a larger gap than in Germany, Italy or Spain, though much less than in France (121\%) and the US (183\%). Having a higher rather than lower secondlevel qualification also makes a difference, with the size of this gap on average not being distinctive for Britain but particularly large in the US. 
Table 7: Regression Analysis of Size of Transfers via Inheritances and Gifts

\begin{tabular}{|c|c|c|c|c|}
\hline & \multicolumn{4}{|c|}{ Britain } \\
\hline & Estimate & $\operatorname{Pr}(>|t|)$ & Est. Exp. & $\begin{array}{l}\% \text { Impact } \\
\text { per unit }\end{array}$ \\
\hline Intercept & 10.123 & 0.000 & 24921 & \\
\hline Age (each year over 40$)$ & 0.024 & 0.000 & 1.025 & 2.5 \\
\hline Male Head & -0.034 & 0.518 & 0.966 & -3.4 \\
\hline Higher Secondary Education & 0.224 & 0.000 & 1.251 & 25.1 \\
\hline Tertiary Education & 0.517 & 0.000 & 1.677 & 67.7 \\
\hline \multirow[t]{3}{*}{ Gender-Age Interaction } & 0.004 & 0.074 & 1.004 & 0.4 \\
\hline & \multicolumn{4}{|c|}{ France } \\
\hline & Estimate & $\operatorname{Pr}(>|t|)$ & Est. Exp. & $\begin{array}{c}\% \text { Impact } \\
\text { per unit }\end{array}$ \\
\hline Intercept & 10.235 & 0.000 & 27873 & \\
\hline Age (each year over 40$)$ & 0.024 & 0.000 & 1.024 & 2.4 \\
\hline Male Head & 0.062 & 0.251 & 1.064 & 6.4 \\
\hline Higher Secondary Education & 0.329 & 0.000 & 1.390 & 39.0 \\
\hline Tertiary Education & 0.793 & 0.000 & 2.210 & 121.0 \\
\hline \multirow[t]{3}{*}{ Gender-Age Interaction } & 0.004 & 0.107 & 1.004 & 0.4 \\
\hline & \multicolumn{4}{|c|}{ Germany } \\
\hline & Estimate & $\operatorname{Pr}(>|t|)$ & Est. Exp. & $\begin{array}{l}\text { \% Impact } \\
\text { per unit }\end{array}$ \\
\hline Intercept & 10.859 & 0.000 & 51990 & \\
\hline Age (each year over 40$)$ & 0.015 & 0.000 & 1.015 & 1.5 \\
\hline Male Head & 0.197 & 0.058 & 1.217 & 21.7 \\
\hline Higher Secondary Education & 0.158 & 0.258 & 1.171 & 17.1 \\
\hline Tertiary Education & 0.479 & 0.001 & 1.615 & 61.5 \\
\hline \multirow[t]{3}{*}{ Gender-Age Interaction } & -0.004 & 0.392 & 0.996 & -0.4 \\
\hline & \multicolumn{4}{|c|}{ Italy } \\
\hline & Estimate & $\operatorname{Pr}(>|t|)$ & Est. Exp. & $\begin{array}{c}\% \text { Impact } \\
\text { per unit }\end{array}$ \\
\hline Intercept & 11.703 & 0.000 & 120903 & \\
\hline Age (each year over 40$)$ & 0.006 & 0.005 & 1.006 & 0.6 \\
\hline Male Head & 0.162 & 0.036 & 1.176 & 17.6 \\
\hline Higher Secondary Education & 0.290 & 0.000 & 1.336 & 33.6 \\
\hline Tertiary Education & 0.449 & 0.000 & 1.567 & 56.7 \\
\hline Gender-Age Interaction & -0.002 & 0.495 & 0.998 & -0.2 \\
\hline
\end{tabular}




\begin{tabular}{|c|c|c|c|c|}
\hline & \multicolumn{4}{|c|}{ Spain } \\
\hline & Estimate & $\operatorname{Pr}(>|t|)$ & Est. Exp. & $\begin{array}{c}\% \text { Impact } \\
\text { per unit }\end{array}$ \\
\hline Intercept & 11.209 & 0.000 & 73819 & \\
\hline Age (each year over 40$)$ & 0.008 & 0.008 & 1.008 & 0.8 \\
\hline Male Head & -0.143 & 0.113 & 0.867 & -13.3 \\
\hline Higher Secondary Education & 0.274 & 0.003 & 1.316 & 31.6 \\
\hline Tertiary Education & 0.320 & 0.000 & 1.377 & 37.7 \\
\hline \multirow[t]{3}{*}{ Gender-Age Interaction } & 0.000 & 0.998 & 1.000 & 0.0 \\
\hline & \multicolumn{4}{|c|}{ US } \\
\hline & Estimate & $\operatorname{Pr}(>|t|)$ & Est. Exp. & $\begin{array}{c}\% \text { Impact } \\
\text { per unit }\end{array}$ \\
\hline Intercept & 10.385 & 0.000 & 32357 & \\
\hline Age (each year over 40$)$ & 0.020 & 0.000 & 1.020 & 2.0 \\
\hline Male Head & 0.084 & 0.468 & 1.088 & 8.8 \\
\hline Higher Secondary Education & 0.506 & 0.000 & 1.658 & 65.8 \\
\hline Tertiary Education & 1.039 & 0.000 & 2.827 & 182.7 \\
\hline Gender-Age Interaction & -0.003 & 0.501 & 0.997 & -0.3 \\
\hline
\end{tabular}

Note: Probabilities in bold are statistically significant from zero at the 1\% level; those in italics are significant at the 5\% level.

The overall relationship between transfer receipt and current household income can be more easily seen from a one-step model encompassing cases where transfer amounts are zero and positive, which we implement by fitting a Poisson regression with splines to capture the distinctive features of the relationship in different parts of the income distribution. ${ }^{8}$ Figure 1 show the predicted transfers received from this model by income for three different education levels, with the three dotted vertical lines marking the $20^{\text {th }}, 50^{\text {th }}$ and $80^{\text {th }}$ percentiles of the equivalent income distribution. This highlights that the expected level of intergenerational transfers is low across the first tranche of the income distribution in all these countries. In Britain, France, and Germany at low incomes the association with income is flat (or even slightly negative); it then 'takes off' after about the $20^{\text {th }}$ percentile, having the highest slope in the broad middle part of the distribution, and flattening at the very high incomes. In Italy the relation is almost linear across the entire distribution, while Spain and the US present a different shape, with a flatter slope around the middle of the distribution and a stronger association with income at the tails.

\footnotetext{
${ }^{8}$ The specification employed has 4 splines and 6 knots at key points of each equivalent income distribution $\left(5^{\text {th }}, 20^{\text {th }}, 50^{\text {th }}, 80^{\text {th }}, 95^{\text {th }}\right.$ and $99^{\text {th }}$ percentiles) which allow for different trajectories of the income-transfer relation at various points in the distribution.
} 

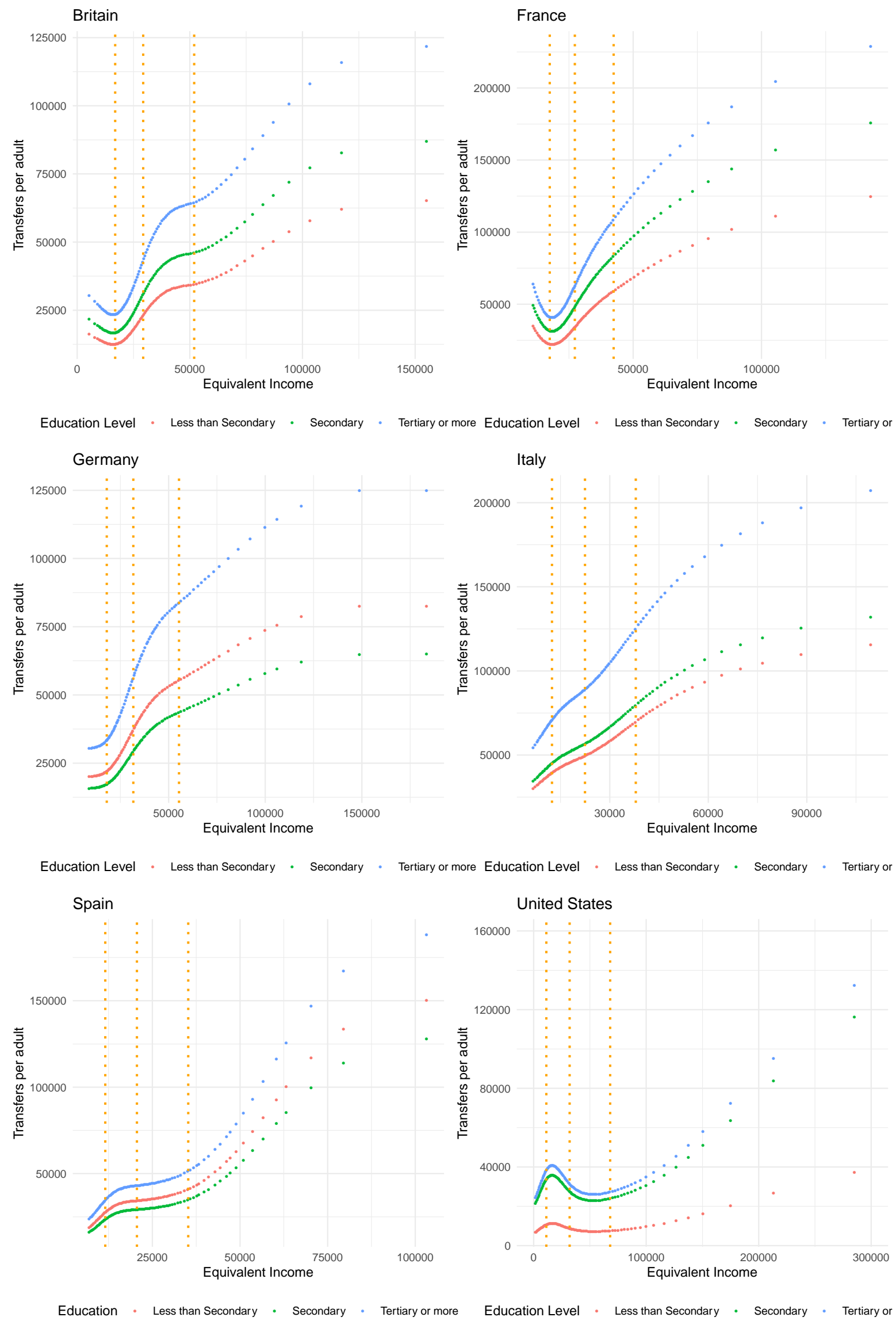

Figure 1: Wealth Transfer Amount (Predicted) by Income and Education 
The level of transfers expected/predicted is also generally larger for higher levels of education across the income distribution, undoubtedly also reflecting other factors (such as social class) that underlie the pattern of intergenerational transfer. The inflexion point in income terms is similar across the three education levels distinguished, but the slope with income tends to increase more rapidly for higher educated households than for lower educated in most countries. The gap between education levels is seen across the income distribution, but in Italy the gap separating the highly educated from others is particularly large, while in the US households with less than completed secondary education stand out with a much lower transfer amount than others across the income distribution.

\section{Intergenerational Transfers and Household Wealth}

\subsection{Intergenerational Wealth Transfers and Wealth Levels}

We now focus on the impact that intergenerational transfers may have had on the wealth of the recipients. This is a highly complex and contested topic, as noted earlier. To shed some light on it in a comparative perspective we first compare the wealth of households that did versus did not receive transfers, and then estimate a regression model for the relationship between transfer receipt and wealth controlling for age, gender, education and household size and their interactions.

Table 8 first shows that the average wealth of transfer recipients is much higher than that of non-recipients in all countries, with that gap being particularly wide in the US. It then compares the proportion of transfer recipients and non-recipients households that have different types of wealth, distinguishing main residence, other real wealth, and financial and business assets. The most marked differences are generally for main residence wealth, whereas the gap for other real wealth is less marked and for financial and business wealth is even smaller. 
Table 8. Wealth for Transfer Recipient versus Non-recipient Households

\begin{tabular}{|c|c|c|c|c|c|c|}
\hline & Britain & France & Germany & Italy & Spain & US \\
\hline Mean Wealth: & $£$ & $€$ & $€$ & $€$ & $€$ & $\$$ \\
\hline Transfer Recipients & 149,418 & 142,857 & 99,797 & 129,323 & 206,804 & 370,000 \\
\hline Non-recipients & 341,527 & 353,383 & 337,774 & 331,391 & 450,537 & 950,000 \\
\hline \multirow[t]{2}{*}{$\begin{array}{l}\text { Ratio recipients/non- } \\
\text { recipients }\end{array}$} & 2.29 & 2.47 & 3.38 & 2.56 & 2.18 & 2.57 \\
\hline & \multicolumn{6}{|c|}{ Share having each type of wealth } \\
\hline Transfer Recipients: & $\%$ & $\%$ & $\%$ & $\%$ & $\%$ & $\%$ \\
\hline Main Residence & 84 & 73 & 72 & 94 & 93 & 85 \\
\hline Other Real Wealth & 90 & 100 & 88 & 97 & 90 & 94 \\
\hline $\begin{array}{l}\text { Financial and } \\
\text { Business Wealth }\end{array}$ & 100 & 100 & 99 & 90 & 97 & 99 \\
\hline Non-Recipients: & $\%$ & $\%$ & $\%$ & $\%$ & $\%$ & $\%$ \\
\hline Main Residence & 60 & 48 & 31 & 56 & 80 & 62 \\
\hline Other Real Wealth & 73 & 100 & 67 & 94 & 80 & 87 \\
\hline $\begin{array}{l}\text { Financial and } \\
\text { Business Wealth }\end{array}$ & 99 & 99 & 97 & 84 & 95 & 95 \\
\hline
\end{tabular}

These 'gross' comparisons between transfer recipients and non-recipients do not take into account that these households differ in a variety of other ways that also influence their wealth, such as age, gender, household size or educational levels. For example, households with an older head are more likely to have received a transfer but may also have higher wealth due to lifetime savings. We take this into account by estimating the impact of transfer receipt on wealth and its constituents in a regression model controlling for age, gender, education and household size and their interactions:

$$
\begin{aligned}
& W_{i}=\hat{\beta} T_{i}+\hat{\pi} S_{i}+\hat{\tau} E_{1_{i}}+\hat{o} E_{2_{i}}+\sum_{n=1}^{4} \hat{\lambda}_{n} A_{i}{ }^{n}+\sum_{n=1}^{4} \widehat{\varpi}_{n} Q_{i}{ }^{n}+\sum_{n=1}^{4} \hat{\zeta}_{n}\left(S_{i} * A_{i}\right)^{n}+ \\
& \sum_{n=1}^{2} \theta_{n}\left(Q_{i} * S_{i}\right)^{n}+\sum_{n=1}^{2} \zeta_{n}\left(E_{1_{i}} * A_{i}\right)^{n}+\sum_{n=1}^{2} \varphi_{n}\left(E_{2_{i}} * A_{i}\right)^{n}+\hat{\varepsilon}_{i},
\end{aligned}
$$

where $T_{i}$ is a dummy variable for whether the household has received an intergenerational transfer, and $\beta$ is the coefficient of primary interest, the estimated impact on household net wealth $W_{i}$ of that receipt. $A_{i}, S_{i}, E_{i}$ and $Q_{i}$ are controls for the age, gender and education of the 
household reference person and for household size. (Detailed estimation results are available on request.)

Table 9 shows that the net wealth gap between wealth transfer recipients and non-recipients estimated in this fashion, having incorporated these controls, is considerably smaller than the gross difference - that gap is reduced by almost one-quarter for Britain, and by more than that for the US. None the less, the net gap having controlled for age, gender, education and household size remains substantial. Clearly a range of characteristics not included in the model, correlated with intergenerational transfer receipt but impacting through different channels, may well be contributing to the remaining gap, including the various ways in which advantaged parents seek to transmit those advantages to their children other than via direct wealth transfers.

Table 9. Wealth Gaps Between Wealth Transfer Recipients and Non-recipients

\begin{tabular}{lcccccc}
\hline & Britain & France & Germany & Italy & Spain & US \\
\hline Gross gap & 192,109 & 210,526 & 237,977 & 202,068 & 243,733 & 580,000 \\
Net gap & 148,614 & 148,317 & 181,333 & 138,264 & 195,317 & 353,111 \\
Net gap as \% gross & 77.4 & 70.5 & 76.2 & 68.4 & 80.1 & 60.9 \\
gap & & & & & & \\
$\%$ contribution to net & & & & & & \\
gap from: & 43 & 32 & 42 & 51 & 16 & 18 \\
Main Residence & 12 & 40 & 29 & 31 & 53 & 21 \\
$\begin{array}{l}\text { Other Real Wealth } \\
\text { Financial and }\end{array}$ & 44 & 29 & 29 & 18 & 31 & 60 \\
Business Wealth & & & & & & \\
\hline
\end{tabular}

Estimating separate regressions of the same form for the different components of net wealth allows us to decompose the overall effect of transfers into impacts on these different components. The lower part of Table 9 shows that, controlling for households' characteristics, main residence wealth accounts for a relatively large proportion of the total net gap for Britain, Germany and Italy. Financial and business wealth is also important in Britain but even more so in the US, where it accounts for more than half of the net wealth gap.

\subsection{The Impact of Intergenerational Transfers on Wealth Inequality}

Having examined the impact of intergenerational transfers on the wealth of the households receiving them, we now turn to the even more tangled question of their influence on overall 
wealth inequality. While a number of recent studies see inheritance as equalising rather than dis-equalising, as noted in Section 2, the underlying assumptions and logic need to be carefully teased out. From the perspective of decomposition approaches such as that applied by for example Crawford and Hood (2016) with British data, the fact that the Gini coefficient for wealth generated from transfers ${ }^{9}$ is found to be higher than that for 'non-transfer wealth' and total wealth is taken to mean that transfers are equalising - incorporating transfer wealth into the picture, going from 'non-transfer wealth to total wealth, reduces measured inequality. As Crawford and Hood point out, what drives this result is that while inheritances are smaller in absolute terms for those lower down the wealth distribution, they are more important relative to other wealth holdings in that part of the distribution, and hence reduce inequality on a relative measure. This has parallels with the findings of Boserup et al. (2016) and Elinder et al. (2018), based on tracing changes in wealth over time at micro-level in Danish and Swedish tax data respectively, that inheritances reduce relative wealth inequality, as measured by the Gini coefficient or top wealth shares, but increase absolute dispersion because even though richer heirs inherit larger absolute amounts, less wealthy heirs inherit more relative to their preinheritance wealth.

However, the counterfactual or point of comparison involved, in effect that there would be no wealth transfers, is arguably not the most relevant in assessing the role of those transfers. Instead, it may be more relevant to ask what the wealth distribution would look like if transfers were distributed differently, or if there were more or fewer transfers than we observe. The latter perspective underlies the analysis we implement building upon the (recentered) influence function (RIF) regression methods proposed in Firpo et al. (2009), which capture how marginal changes in the distribution of covariates impact on distributive statistics. We apply these methods to calculate the effect that a marginal increase in the number of households in receipt of transfers would have on the overall shape of the wealth distribution, holding constant the wealth distributions conditional on the transfer. Substituting recipient households for ones that are equivalent in terms of other observed characteristics but have not received transfers, we can see what impact this has on the distribution. If transfers have no impact and the two groups are similar, such a substitution would leave the wealth distribution unchanged. If, on the other hand the wealth of recipients differs substantially from the wealth of non-recipients, the

\footnotetext{
${ }^{9}$ In deriving an estimate of 'transfer wealth' a return on transfer amounts received since the date of receipt is imputed, with a standard rate applied to all recipients.
} 
substitution will transform the shape of the overall distribution in possibly complicated ways. Looking at how various indicators - the mean, percentiles and inequality measures - respond to such substitutions therefore represents an indirect way to assess how transfers contribute to the shape of the overall wealth distribution. (Like decomposition approaches, this is clearly descriptive or 'static' rather than attempting to identify causal or general equilibrium impacts of intergenerational transfers on the total wealth distribution.)

The RIF regression approach has several advantages over conventional inequality decomposition methods. The first is that RIF regressions apply generally to any conventional statistic of interest, not only to specific decomposable measures such as the Gini coefficient, including alternative summary inequality measures and top income or wealth shares. Second, and even more importantly, they allow us to assess the distributive impact of transfer receipt not only 'unconditionally' but also 'conditionally', that is, holding constant covariates such as age and gender that may also influence wealth. (For details on the method and the extension on Firpo et al involved, see Choe and Van Kerm, 2018.) In essence, the method probes what the wealth distribution be expected to look like if there were more transfer recipients and fewer non-recipients, or more recipients of large versus medium versus small transfers, with everything else held constant? This impact will then depend on the locations in the wealth distributions of recipients versus non-recipients, and the size of the receipt. We distinguish between amounts up to the median receipt, which we term 'small', amounts from the median up to the $90^{\text {th }}$ percentile of receipts, which we term 'medium', and amounts greater than the $90^{\text {th }}$ percentile, which we call 'large' transfer amounts. In applying this method we restrict the analysis to households with reference person over 50 years of age, to limit the role of purely age-related variation and allow us to hone in on the impact of transfers received.

Table 10 shows the estimated impact that a marginal increase in the proportion of transfer recipients of various types would have on the Gini coefficient for total wealth for all transfers and then distinguishing transfers of different sizes, together with significance levels. Figure 2 then illustrates these estimated impacts. 
Table 10. Estimated Influence of Wealth Transfer Receipts of Differing Sizes on the Gini Index for Wealth

\begin{tabular}{|c|c|c|c|c|c|c|}
\hline Country & Transfer Size & Estimate & SE & p-value & lower limit & upper limit \\
\hline \multirow{4}{*}{ Britain } & All & -0.0057 & 0.0018 & 0.0016 & -0.0093 & -0.0022 \\
\hline & Large & 0.0171 & 0.0082 & 0.0371 & 0.0010 & 0.0332 \\
\hline & Medium & -0.0113 & 0.0021 & 0.0000 & -0.0154 & -0.0072 \\
\hline & Small & -0.0075 & 0.0023 & 0.0010 & -0.0120 & -0.0030 \\
\hline \multirow{4}{*}{ France } & All & -0.0061 & 0.0021 & 0.0041 & -0.0102 & -0.0019 \\
\hline & Large & 0.0238 & 0.0062 & 0.0001 & 0.0116 & 0.0360 \\
\hline & Medium & -0.0094 & 0.0041 & 0.0213 & -0.0175 & -0.0014 \\
\hline & Small & -0.0102 & 0.0012 & 0.0000 & -0.0127 & -0.0078 \\
\hline \multirow{4}{*}{ Germany } & All & -0.0179 & 0.0039 & 0.0000 & -0.0254 & -0.0103 \\
\hline & Large & 0.0284 & 0.0192 & 0.1384 & -0.0092 & 0.0660 \\
\hline & Medium & -0.0340 & 0.0038 & 0.0000 & -0.0414 & -0.0266 \\
\hline & Small & -0.0144 & 0.0034 & 0.0000 & -0.0211 & -0.0078 \\
\hline \multirow{4}{*}{ Italy } & All & -0.0080 & 0.0020 & 0.0001 & -0.0121 & -0.0040 \\
\hline & Large & 0.0411 & 0.0171 & 0.0163 & 0.0076 & 0.0746 \\
\hline & Medium & -0.0204 & 0.0021 & 0.0000 & -0.0245 & -0.0162 \\
\hline & Small & -0.0091 & 0.0013 & 0.0000 & -0.0116 & -0.0066 \\
\hline \multirow{4}{*}{ Spain } & All & 0.0067 & 0.0035 & 0.0560 & -0.0002 & 0.0136 \\
\hline & Large & 0.0855 & 0.0362 & 0.0180 & 0.0147 & 0.1564 \\
\hline & Medium & -0.0030 & 0.0033 & 0.3728 & -0.0095 & 0.0036 \\
\hline & Small & 0.0021 & 0.0032 & 0.5104 & -0.0042 & 0.0084 \\
\hline \multirow{4}{*}{ US } & All & -0.0062 & 0.0015 & 0.0000 & -0.0091 & -0.0033 \\
\hline & Large & 0.0185 & 0.0086 & 0.0317 & 0.0016 & 0.0354 \\
\hline & Medium & -0.0139 & 0.0017 & 0.0000 & -0.0173 & -0.0104 \\
\hline & Small & -0.0067 & 0.0017 & 0.0001 & -0.0100 & -0.0035 \\
\hline
\end{tabular}




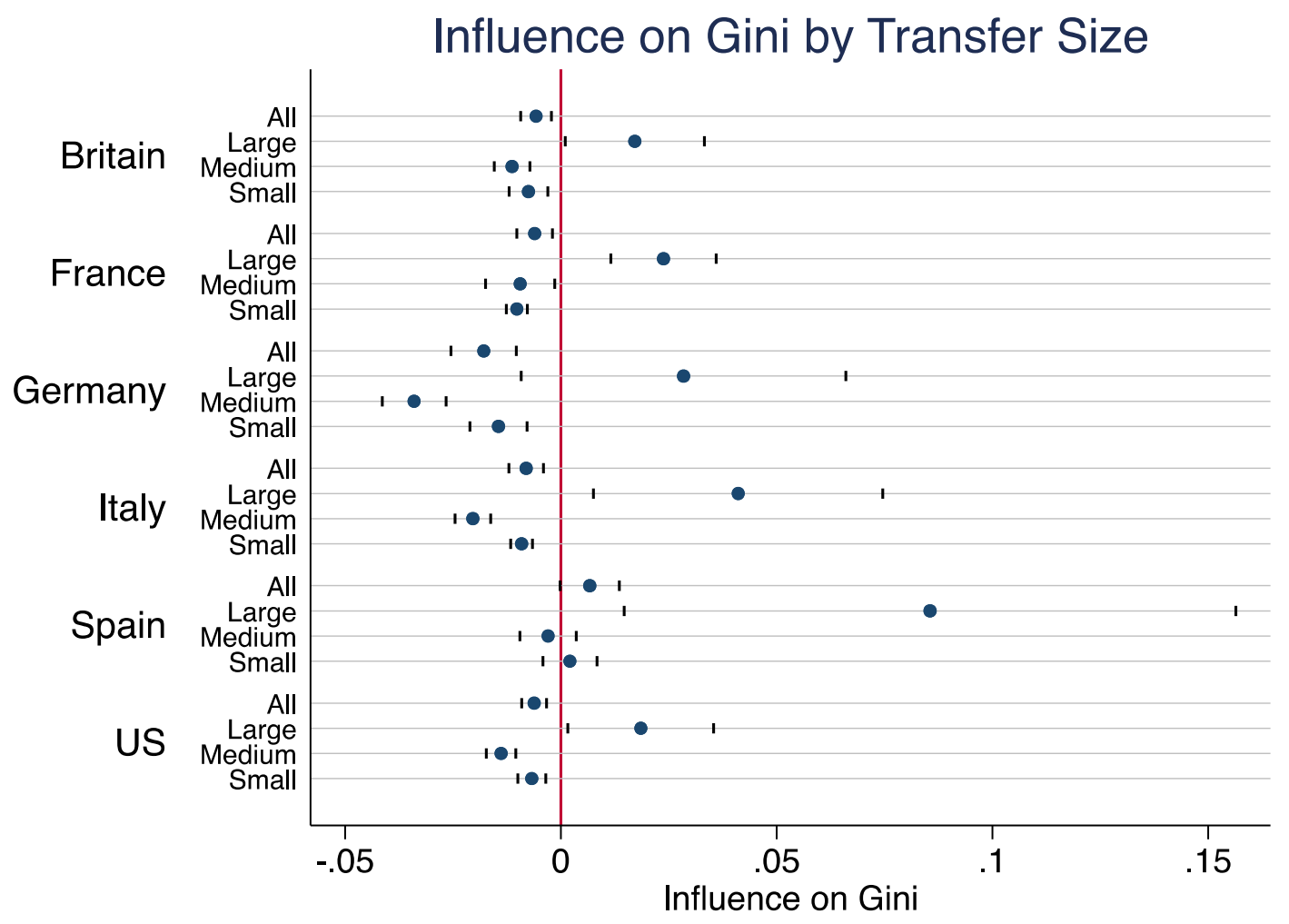

\section{Figure 2. Estimated Influence of Wealth Transfer Receipts of Differing Sizes on the Gini Index for Wealth}

(Estimates from RIF-Gini regression with age, gender and household sizes controls)

These bring out that the impact of transfer receipts in the Gini depends on the size of transfer involved. The first line for each country in Table 9 and Figure 2 shows the effect of an increase in the share of households receiving transfers of any size. The impact of having more recipients and fewer non-recipients would be to reduce the Gini - reduce overall wealth inequality- in all countries except Spain. This reduction is larger in some countries than others, but in all countries it is statistically significant. What this reflects is the fact that transfer recipients are, on the whole, more frequently positioned around the middle of the overall wealth distribution than non-recipients, because a considerable number of the latter are towards the bottom of the wealth distribution, with very little or no wealth. Increasing the proportion of transfer recipients serves to increase the number of households in the middle of the distribution, to which the Gini coefficient is particularly (negatively) sensitive.

We also see that a similar inequality-reducing impact is found when we consider only small transfers (below the median value) and even more so medium-sized inheritances (between the $50^{\text {th }}$ and the $90^{\text {th }}$ percentile of the value of transfers). Since most recipients of small and medium 
transfers are in the central part of the distribution, increasing their share would again have an equalising effect. However, when we consider the receipt of large inheritances the influence on the Gini index is positive, in other words increasing the weight of large inheritance recipients in the overall distribution would increase inequality. What this reveal is that large transfers recipients tend to be found in the upper tail of the distribution: more large transfer recipients would tend to push inequality upwards.

It is interesting to test the sensitivity of these results to the inequality measure employed, by carrying out a similar analysis with a different inequality measure, namely the ratio between the wealth held by the top $5 \%$ and the bottom $95 \%$ of the distribution. Figure 3 shows that this produces rather similar results. The influence of large transfers receipt is again clearly disequalising, having a significant increasing impact on this inequality measure. On the other hand, receipt of small, medium and overall transfers seems to have an equalising effect in this measure in all countries, and more strongly in Germany and the US. However, in most countries that influence is not as clearly significant as it was when the Gini was employed.

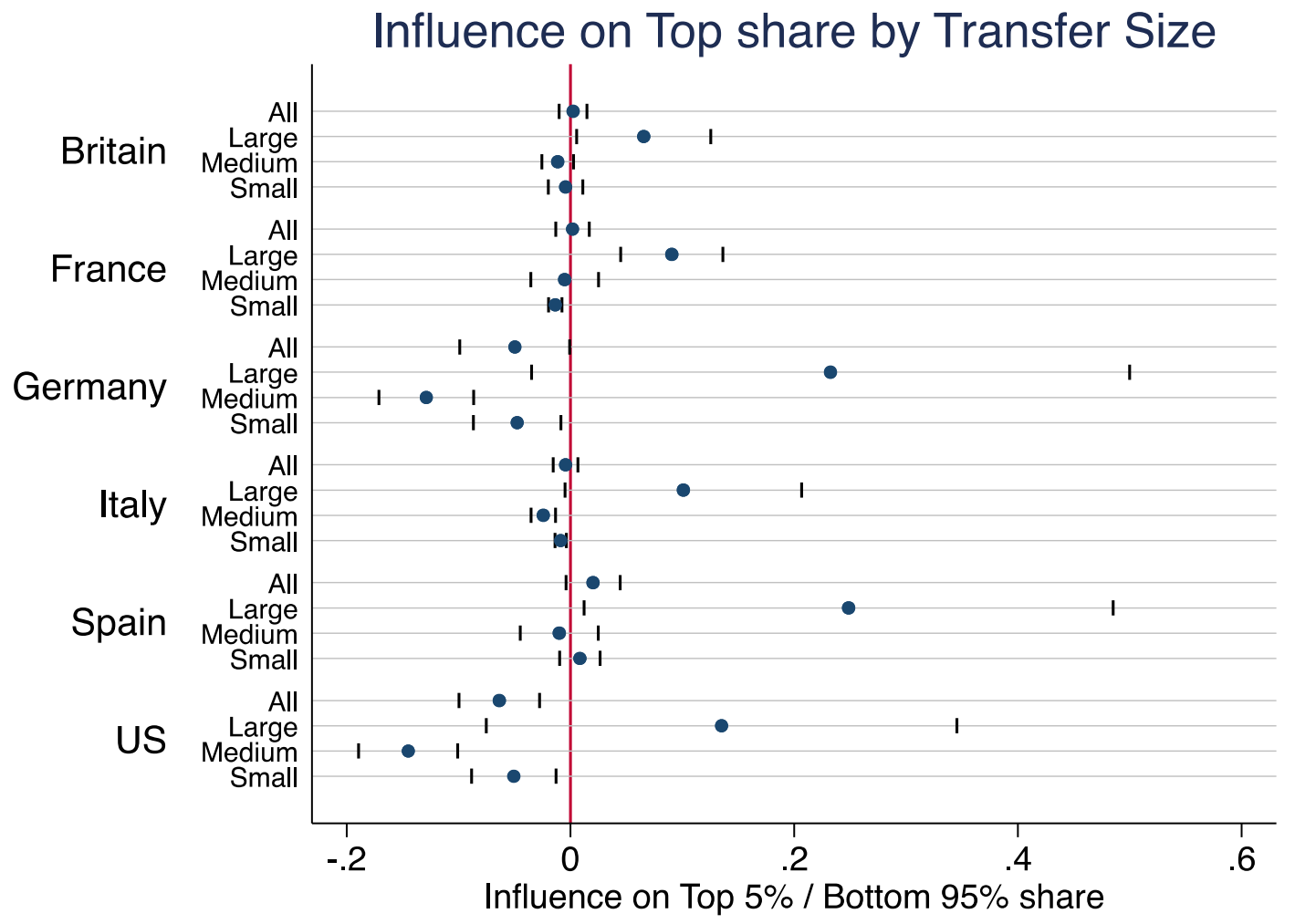

Figure 3. Influence on the Ratio of the Top 5\% to Bottom 95\% Wealth Shares of Wealth Transfer Receipts of Different Sizes

(From a RIF regression with age, gender and household sizes controls) 


\section{Conclusions}

While comparative research on household wealth inequality has been growing, exploiting the recent much improved availability of survey data, studies of wealth transfers across countries are much rarer and so far mostly confined to Eurozone countries. This paper has presented a comparative investigation of patterns of intergenerational wealth transfer reported in household wealth surveys for six major developed economies - Britain, France, Germany, Italy, Spain and the US. It has also sought to assess the role that receipt of intergenerational wealth transfers plays in observed levels of household wealth and wealth inequality in a comparative framework. These receipts can have been at any time in the past, and in the form of inheritances or gifts inter vivos.

We found that in most of these countries about one-third of households surveyed report having received some intergenerational wealth transfer, but that figure was only one-fifth in the US. While some younger respondents (aged under 35) did report receipts these were often relatively small in size, so generally only about $5 \%$ of the total amount reported in transfers had been received by that age group. In Britain, France, Italy, and the US those aged 65 or more received the largest share of the total, whereas the 'middle-aged' did so in Germany and Spain. Ranking households by current gross (equivalised) income, households in the top quartile generally received $40 \%-50 \%$ of the total amount transferred, compared with about 10\%-15\% going to the bottom quartile. Ranking by wealth rather than income, a substantial proportion of those currently in the top $1 \%$ of the distribution did not benefit from receipt of intergenerational transfers, but those who did received particularly large amounts on average. By contrast, those in the bottom quarter of the wealth distribution received very little of total transfers.

Estimated models for transfers received showed that age and education were powerful predictors. The relative advantage of those with tertiary education in terms of transfer amounts received varied across countries and was particularly pronounced in the cases of Britain, France and the US. The predicted level of intergenerational transfers was also consistently low across the bottom part of the income distribution, controlling for other characteristics.

We then focused on the relationship between intergenerational wealth transfers received and current wealth levels. Before taking other features into account, a substantial gap in net wealth between those who did not versus did report having received some transfer was seen in the 
European countries, a gap that was considerably wider in the US. Controlling for age, gender and education together with household size reduced the size of the wealth gap between transfer recipients and non-recipients but it remained substantial. The relationship between transfer receipt and owning one's own house generally accounted for a substantial proportion of this difference, but for Britain and even more so the US financial and business wealth also played a major role.

We then employed influence function regressions to estimate the impact a marginal counterfactual increase in the proportion of recipients of transfers of differing sizes would have on the overall shape of the wealth distribution. The results suggested that in most countries, having more transfer recipients and correspondingly fewer non-recipients, or more recipients of small or medium-sized transfers, would be expected to reduce wealth inequality modestly, reflecting the fact that those transfer recipients were more concentrated around the middle of the wealth distribution than non-recipients. In contrast, increasing the proportion of recipients of large transfers generally increased overall wealth inequality. These findings serve to reinforce the notion that the overall effect of intergenerational wealth transfers may be equalising, but highlights a crucial heterogeneity in impact depending of the size of the transfers that has not been recognised before.

While this exercise is clearly static in nature, the counterfactual involved in assessing the impact of intergenerational transfers is arguably more relevant than in analyses that compare the observed distribution with what is might be in the absence of transfers. While adequately capturing and incorporating behavioural responses to transfer receipt or non-receipt is clearly a key priority, so is the teasing out of the most appropriate point of comparison against which their impact on wealth inequality is to be assessed. The implications for policy, most obviously with respect to taxation of wealth transfers, also require careful teasing out: especially in light of their disequalising impact in terms of overall wealth inequality, strengthening the capacity to effectively tax large transfers would constitute a key element in that regard. 


\section{References}

Acciari, P., and S. Morelli (2020), "Wealth Transfers and Net Wealth at Death: Evidence from the Italian Inheritance Tax Records 1995-2016" Chapter in forthcoming NBER book "Measuring and Understanding the Distribution and Intra/Inter-Generational Mobility of Income and Wealth", Raj Chetty, John N. Friedman, Janet C. Gornick, Barry Johnson, and Arthur Kennickell, editors. Conference held March 5-6, 2020. Forthcoming from University of Chicago Press in NBER Book Series Studies in Income and Wealth

Alvaredo, F., A. B. Atkinson, and S. Morelli (2018), 'Top Wealth Shares in the UK over More than a Century', Journal of Public Economics, 162: 26-47.

Balestra, C. and Tonkins, R. (2018) Inequalities in household wealth across OECD countries: Evidence from the OECD Wealth Distribution Database, Statistics and Data Directorate Working Paper No. 88, Paris: OECD.

Boserup, S., W. Kopczuk, and C. Kreiner (2016), 'Wealth Inequality: Evidence from the Role of Bequests in Shaping Wealth Inequality', American Economic Review, 106(5): 656-61.

Bricker, J., A. Henriques, J. Krimmel, and J. Sabelhaus (2016), 'Estimating Top Income and Wealth Shares: Sensitivity to Data and Methods', American Economic Review, 106(5): 64145.

Bricker, J., A. Henriques, and K. Moore (2017), Updates to the Sampling of Wealthy Families in the Survey of Consumer Finances, Finance and Economics Discussion Series 2017-114, Washington: Board of Governors of the Federal Reserve System, https://doi.org/10.17016/FEDS.2017.114.

Choe, C. and P. Van Kerm, (2018), 'Foreign Workers and the Wage Distribution: What Does the Influence Function Reveal?', Econometrics 2018, 6(3), 41

Cowell, F., B. Nolan, J. Olivera and P. Van Kerm (2018), 'Wealth, Top Incomes and Inequality', in K. Hamilton and C. Hepburn (eds.), National Wealth What is Missing, Why it Matters, Oxford: Oxford University Press.

Crawford, R. and A. Hood (2016), 'Lifetime Receipt of Inheritances and the Distribution of Wealth in England', Fiscal Studies, 37(1): 55-75.

Davies, J.B. and A.F. Shorrocks (2000), 'The distribution of wealth', in A.B. Atkinson and F. Bourguignon (eds.), Handbook of Income Distribution, Vol. 1, Amsterdam: North Holland.

Elinder, M., O. Erixson, and D. Waldenström (2018), 'Inheritance and Wealth Inequality: Evidence from Population Registers', Journal of Public Economics, 165: 17-30.

European Central Bank (2012), HFCS Euro Area Questionnaire, Wave 1, Frankfurt: European Central Bank. 
Household Finance and Consumption Network (2013), The Eurosystem Household Finance and Consumption Survey: Methodological Report for the First Wave, Statistics Paper Series No. 1, European Central Bank.

Household Finance and Consumption Network (2016), The Household Finance and Consumption Survey: Methodological Report for the Second Wave, Statistics Paper Series No. 16, European Centreal Bank.

Fessler, P., P. Mooslechner, and M. Schürz (2008), How Inheritances Relate to Wealth Distribution? Theoretical Reasoning and Empirical Evidence on the Basis of LWS Data, Luxembourg Wealth Study Working Paper Series Working Paper No. 6, Luxembourg: LWS. Fessler, P. and M. Schürz (2018), 'Private Wealth Across European Countries: The Role of Income, Inheritance and the Welfare State', Journal of Human Development and Capabilities, 19(4): 521-49.

Firpo, S., N. Fortin, and T. Lemieux (2009), 'Unconditional quantile regressions', Econometrica 77: 953-73.

Karagiannaki, E. (2011) Recent trends in the size and the distribution of inherited wealth in the UK, Casepaper 146, London: London School of Economics.

Karagiannaki (2015), 'Recent Trends in the Size and the Distribution of Inherited Wealth in the UK', Fiscal Studies, 36 (2), 181-213.

Karagiannaki, E. (2017), 'The Impact of Inheritance on the Distribution of Wealth: Evidence from Great Britain', Review of Income and Wealth, 63(2).

Karagiannaki, E. and J. Hills (2013), 'Inheritance, transfers and the distribution of wealth', in J. Hills, F. Bastagli, F. Cowell, H. Glennerster, E. Karagiannaki and A. McKnight (eds), Wealth in the UK: Distribution, Accumulation and Policy, Oxford: Oxford University Press.

Klevmarken, A. (2004), 'On the Wealth Dynamics of Swedish Families, 1984-98', Review of Income and Wealth, 50 (4), 469-91.

Kotlikoff, L. J. and L. H. Summers (1981), 'The role of intergenerational transfers in aggregate capital accumulation', Journal of Political Economy, vol. 89, pp. 706-32.

Leitner, S. (2016), Drivers of Wealth Inequality in Euro-Area Countries, Working Paper 122, Vienna Institute for International Economic Studies, Viennna.

Modigliani, F. (1988), 'Measuring the contribution of intergenerational transfers to total wealth: conceptual issues and empirical findings', in D. Kessler and A. Masson (eds), Modelling the Accumulation and Distribution of Wealth, Oxford: Clarendon Press.

Nekoei, A. and D. Seim (2019), How Do Inheritances Shape Wealth Inequality? Theory and Evidence from Sweden, CEPR Discussion Paper No. DP13199. 
Office for National Statistics (2019), Pension wealth in Great Britain: April 2016 to March 2018, Statistical bulletin, Office for National Statistics.

Piketty, T. (2011), 'On the Long-Run Evolution of Inheritance: France 1820-2050', Quarterly Journal of Economics, 126(3): 1071-1131.

Piketty, T. (2014), Capital in the Twenty-First Century, Cambridge: Harvard University Press. Wolff, E. (2002), 'Inheritances and wealth inequality, 1989-1998', American Economic Review, 92, 260-4.

Wolff, E. and M. Gittleman (2014), 'Inheritances and the distribution of wealth or whatever happened to the great inheritance boom?', Journal of Economic Inequality, 12, 439-68. 


\section{Appendix 1: Wealth Transfers in the British Wealth and Assets Survey}

\section{Missing Data and Imputation}

The first significant issue that must be addressed in doing so is the extent of 'missingness', specifically the number of missing values for amounts received by those who have reported a receipt. For fully $75 \%$ of respondents in Wave 1 who said they had received an inheritance in the past 5 years, there is no value for the amount received, even in terms of the bracketed amount responses allowed (1758 out of 2301 households reporting a first receipt are missing the value, and the corresponding figure for a second inheritance received is 86 out of 112). This reflects the issues that invariably arise with such survey questions in terms of recall, reluctance, etc., but also a problem in the administration of that first wave of the survey in terms of questionnaire design/routing that was corrected in subsequent waves. For the Wave 1 question about inheritances received more than 5 years ago, about $20 \%$ of those who reported such a receipt $(696$ out of 3,401$)$ are missing its value, and that is also the case for $25 \%$ percent of those reporting receipt of a second such inheritance (102 out of 443). By contrast, there are very few missing values for amounts received as gifts in the previous two years in Wave 1 (11 out of the 1,268 who reported having received a gift).

The Office for National Statistics carried out only modest imputation of missing values for inheritances for Wave 3, involving only a handful of observations, but did no imputation of these variables in Waves 1 or 2. Rather than losing all these respondents who have provided the critical information that an inheritance or gift was received but for which no value is present in the dataset, we have applied an imputation procedure for these missing values. This employs the predictive mean imputation method, implemented using the MICE package in R. For Wave 1 , missing values have been imputed for

- The first inheritance reported to have been received in the 5 years before the survey;

- The first inheritance received more than 5 years before the survey by those who reported such a receipt;

- The second inheritance received more than 5 years before the survey by those who reported having received such an inheritance.

The imputation method relies on the values provided by those who did respond to the relevant question - thus, for example, the missing values for the value of the second inheritance received 
longer than 5 years ago are imputed using responses from those who reported receiving such an inheritance and provided a value. Alternative models have been tested, the first using age, number of past inheritances received, number of recent inheritances received, and expectation of future inheritance, and the second adding total household wealth and household income to the model. The PMM method allows the number of discrete imputations run to be selected; here we have taken 5 runs for each individual and check to see whether the use of one iteration versus another affects the results. The imputations have also been flagged in our constructed dataset so that they can be taken into account in the project's statistical modelling to probe the nature and impact of intergenerational transfers.

\section{Net to Gross Inheritance values}

Inheritance questions in the WAS ask for the value of inheritances received "after tax and other deductions", while the HFCS and SCF ask for the gross market value of inheritances. We have estimated pre-tax values from the after-tax figures reported in WAS using the marginal tax rates and thresholds appropriate for each past inheritance (using the year the inheritance was received). The UK had a top marginal rate for bequests (estate duty and capital transfer tax) between $75 \%$ and $85 \%$ from 1949 and 1983, and it decreased gradually until the current flat $40 \%$ inheritance tax was established in 1988.

\section{Excluding 'Small' Receipts}

The final issue that had to be addressed in using data on wealth transfers from WAS relates to a potentially important difference between it and the other data sources in the way in which questions about inheritances and gifts were framed. In both the SCF and the HFCS, respondents were asked whether they had ever received an inheritance or substantial gift, whereas in WAS no such qualifier was used. As a consequence, a greater number of quite small amounts are included in the reported receipts of UK respondents. To bring the datasets into closer alignment, we apply a threshold of 5,000 in national currency terms (2010 values), so receipts lower than that are not included. This has a significant impact on the proportion of UK households reporting receipt of gifts, with a considerably smaller effect elsewhere; the impact on inheritances is marginal. 